\title{
Looking for New Polycrystalline MC-Reinforced Cobalt-Based Superalloys Candidate to Applications at $1200^{\circ} \mathrm{C}$
}

\author{
Patrice Berthod \\ Institut Jean Lamour (CNRS UMR 7198), Faculty of Sciences and Technologies, University of Lorraine, BP 70239, \\ 54506 Vandoeuvre-lès-Nancy, France \\ Correspondence should be addressed to Patrice Berthod; patrice.berthod@univ-lorraine.fr
}

Received 7 December 2016; Revised 17 February 2017; Accepted 22 February 2017; Published 9 March 2017

Academic Editor: Santiago Garcia-Granda

Copyright (C) 2017 Patrice Berthod. This is an open access article distributed under the Creative Commons Attribution License, which permits unrestricted use, distribution, and reproduction in any medium, provided the original work is properly cited.

\begin{abstract}
For applications for which temperatures higher than $1150^{\circ} \mathrm{C}$ can be encountered the currently best superalloys, the $\gamma / \gamma^{\prime}$ single crystals, cannot be used under stress because of the disappearance of their reinforcing $\gamma^{\prime}$ precipitates at such temperatures which are higher than their solvus. Cobalt-based alloys strengthened by refractory and highly stable carbides may represent an alternative solution. In this work the interest was focused on MC carbides of several types. Alloys were elaborated with atomically equivalent quantities in $\mathrm{M}$ element (among Ti, Ta, Nb, Hf, or Zr) and in C. Script-like eutectic TiC, TaC, NbC, HfC, and ZrC carbides were successfully obtained in the interdendritic spaces. Unfortunately, only one type, HfC, demonstrated high morphological stability during about 50 hours at $1200^{\circ} \mathrm{C}$. The concerned alloy, of the Co-25Cr-0.5C-7.4Hf type (in wt.\%), was further characterized in flexural creep resistance and air-oxidation resistance at the same temperature. The creep behaviour was very good, notably by comparison with a more classical Co-25Cr-0.5C-7.5Ta alloy, proving that the interest of HfC is higher than the TaC one. In contrast the oxidation by air was faster and its behaviour not really chromia-forming. Significant improvements of this chemical resistance are expected before taking benefit from the mechanical superiority of this alloy.
\end{abstract}

\section{Introduction}

Many hot applications require high temperature materials which can be ceramics or metallic alloys. Metallic alloys must be especially chosen in case of the existence of tensile stresses applied here or there in the piece, at a moment or at another one during service (turbine blades in aeroengines or power generation plants, glass forming industrial tool, etc.). Many refractory metallic alloys for such uses are known since several decades and are still currently used $[1,2]$. Research and development studies are today intensive to meet increasingly exigent requirements concerning the surface and bulk stabilities at service temperature. Indeed, the working environments are more and more severe (complex mixtures of oxidizing gases, corrosive liquid sulfides, molten CMAS, aggressive molten glasses, etc.), as well as the static or variable mechanical loadings (creep, fatigue, etc.). An important family of refractory alloys developed in the last decades, and remaining among the best efficient ones for particularly severe conditions of use, is the $\gamma / \gamma^{\prime}$ nickel-based single crystals one [3]. More recently, this principle of alloy's strengthening by intermetallic $\mathrm{Ni}_{3} \mathrm{Al}$-type coherent precipitates, initially successfully applied to nickel-based superalloys [4], is now tested for cobalt-based superalloys $[5,6]$. In parallel other directions are also investigated: rhenium-containing cobalt-based alloys $[7,8]$, refractory high entropy alloys [9], and so on.

However, older types of alloys, equiaxed carbidesstrengthened polycrystalline superalloys, have many times demonstrated their interest. They may evolve by replacing the usual chromium or \{chromium + tungsten\} carbides by MC carbides, for example, in chromium-rich cobaltbased alloys [10]. These MC carbides may crystallize at the end of solidification as eutectic carbides, script-like shaped and mixed with the periphery of the matrix dendrites. Furthermore, during new exposures at high temperatures this morphology, favourable to high mechanical properties at elevated temperatures, stays more (cases of $\mathrm{TaC}, \mathrm{HfC}$, and $\mathrm{ZrC}$ ) or less (case of $\mathrm{NbC}$ ) unaltered in $\{\mathrm{Co}-10 \mathrm{Ni}-30 \mathrm{Cr}$, wt.\%\} bases enriched with $\mathrm{C}$ and these MC-former elements $[10,11]$. 
TABLE 1: Physical properties of different types of MC carbides.

\begin{tabular}{|c|c|c|c|c|c|}
\hline Carbide $\rightarrow$ & $\mathrm{TaC}$ & $\mathrm{TiC}$ & $\mathrm{NbC}$ & $\mathrm{HfC}$ & $\mathrm{ZrC}$ \\
\hline Fusion $T_{f}\left({ }^{\circ} \mathrm{C}\right)$ & 2880 & 3147 & 3490 & 3890 & 3530 \\
\hline Volume mass $\rho\left(\mathrm{g} \mathrm{cm}^{3}\right)$ & 14.2 & 4.9 & 7.6 & 12.2 & 6.8 \\
\hline Hardness $\mathrm{HV}_{50 \mathrm{~g}}$ & 1800 & 3000 & 2400 & 3000 & 2900 \\
\hline Thermal expansion coefficient $\alpha, \times 10^{6} \mathrm{~K}^{-1}\left[25-1000^{\circ} \mathrm{C}\right]$ & 6.5 & 8.8 & 7.0 & 6.6 & 6.7 \\
\hline
\end{tabular}

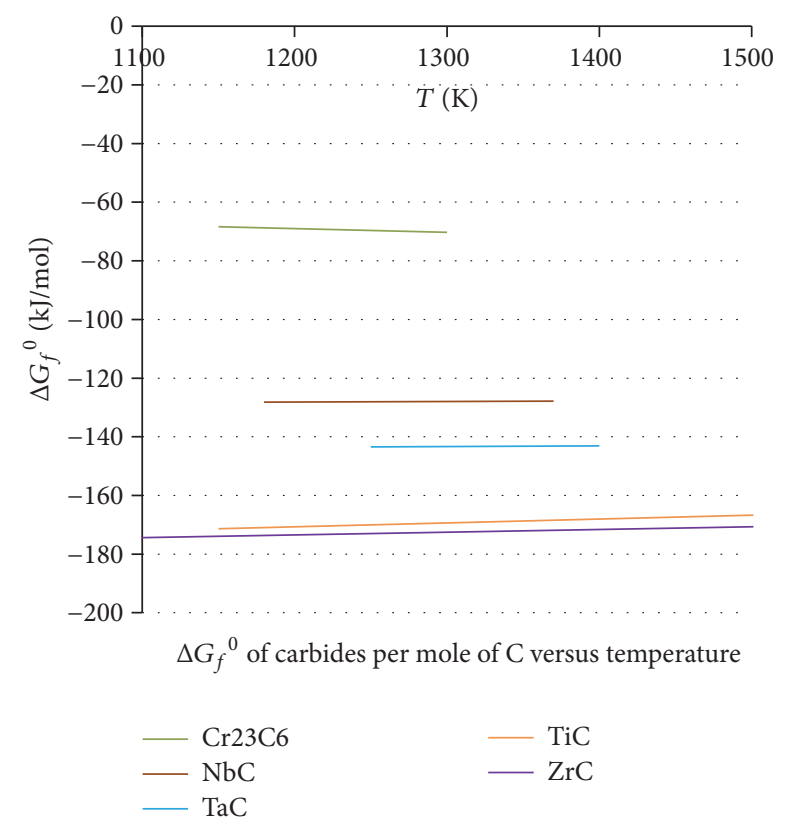

FIGURE 1: Gibbs enthalpies of formation of different carbides versus temperature (relative stabilities).

$1200^{\circ} \mathrm{C}$ is a temperature higher than the solvus temperature of the $\gamma^{\prime}$ precipitates. At so high temperature these ones will be shortly totally dissolved. This is true for the concerned nickel-based and the cobalt-based ones, both consequently becoming mechanically weak. In contrast, some of the MC carbides may be still present even after a long time spent at so high temperature, as already observed in some cases [10]. The purpose of this work is precisely to test the morphology behaviour of several MC carbides at high temperature, to select the best systems, and to start characterizing them in the most important high temperature properties, with creep tests at $1200^{\circ} \mathrm{C}$ and oxidation tests by air at the same temperature.

\section{Experimental Details}

2.1. Selection of the MC-Forming Elements to Study. Many elements belonging to the transition metals of the periodic table allow forming MC carbides. This is the case of titanium, tantalum, niobium, hafnium, and zirconium, for instance. Indeed these elements do form MC carbides which are possibly very stable at high temperature, more than chromium carbides and carbides of the base elements, as suggested by the Ellingham diagram presented in Figure 1, drawn by exploiting thermodynamic data of an earlier work [11].
TABLE 2: Chemical compositions of the studied alloys.

\begin{tabular}{lccccc}
\hline Alloy & $\mathrm{Ni}$ & $\mathrm{Cr}$ & $\mathrm{C}$ & $\mathrm{M}$ & $\mathrm{M}=$ \\
\hline "CoCrC=Ta" & (Bal.) & 25 & 0.5 & 7.5 & $\mathrm{Ta}$ \\
"CoCrC=Ti" & (Bal.) & 25 & 0.5 & 2 & $\mathrm{Ti}$ \\
"CoCrC=Hf” & (Bal.) & 25 & 0.5 & 3.9 & $\mathrm{Nb}$ \\
"CoCrC=Hf" & (Bal.) & 25 & 0.5 & 7.4 & $\mathrm{Hf}$ \\
"CoCrC=Zr" & (Bal.) & 25 & 0.5 & 3.8 & $\mathrm{Zr}$ \\
\hline
\end{tabular}

The hardness and melting points of these MC carbides are very high while their volume masses may be very different when considered element by element (Table 1). For the latter point of view the $\mathrm{TiC}$ carbides appear as being particularly interesting for the total density of the alloys while this is the contrary for the $\mathrm{TaC}$ ones. The volume fraction of these carbides must remain low anyway, to allow the alloys to keep high impact toughness and to avoid too intense problems of mechanical interactions at the microstructure scale between the high thermal expansion matrix ( $\alpha$ of about $15 \times 10^{-6} \mathrm{~K}^{-1}$ ) and low thermal expansion MC carbides.

2.2. Chemical Compositions of the Studied Alloys. The MCformer elements titanium, tantalum, niobium, hafnium, and zirconium were thus selected for this work. A high chromium content was chosen for the alloys to allow them to correctly resist both oxidation and corrosion; it was expected that a $25 \mathrm{wt} . \% \mathrm{Cr}$ content is enough for this role. $0.5 \mathrm{wt} . \%$ was selected for the carbon content to obtain a carbide network dense enough but not interconnected to allow maintaining the impact toughness at a sufficient level. Finally, the $\mathrm{M}$ weight contents in $\mathrm{Ti}, \mathrm{Ta}, \mathrm{Nb}, \mathrm{Hf}$, and $\mathrm{Zr}$ were rated for leading to the same atomic content as the carbon's one. The given names and chemical compositions of all these alloys are gathered in Table 2 .

2.3. Elaboration of the Alloys. All alloys were synthesized by conventional foundry. Charges were prepared from parts of pure elements ( $\mathrm{Ni}, \mathrm{Cr}, \mathrm{Hf}, \mathrm{Ta}, \mathrm{Ti}$, and $\mathrm{Zr}$ from Alfa Aesar and $\mathrm{C}$ as graphite, purity > 99.9 wt.\% for all elements). Melting was achieved in 300 mbars of pure argon using a high frequency induction furnace (CELES, France), protected from outside air by a silica tube. Melting occurred during the heating (which took about three minutes); homogenization of the liquid was realized isothermally during five minutes. Solidification took about thirty seconds and the cooling to room temperature about thirty minutes. Photographs of the furnace and of an ingot obtained by this way are presented in Figure 2. 


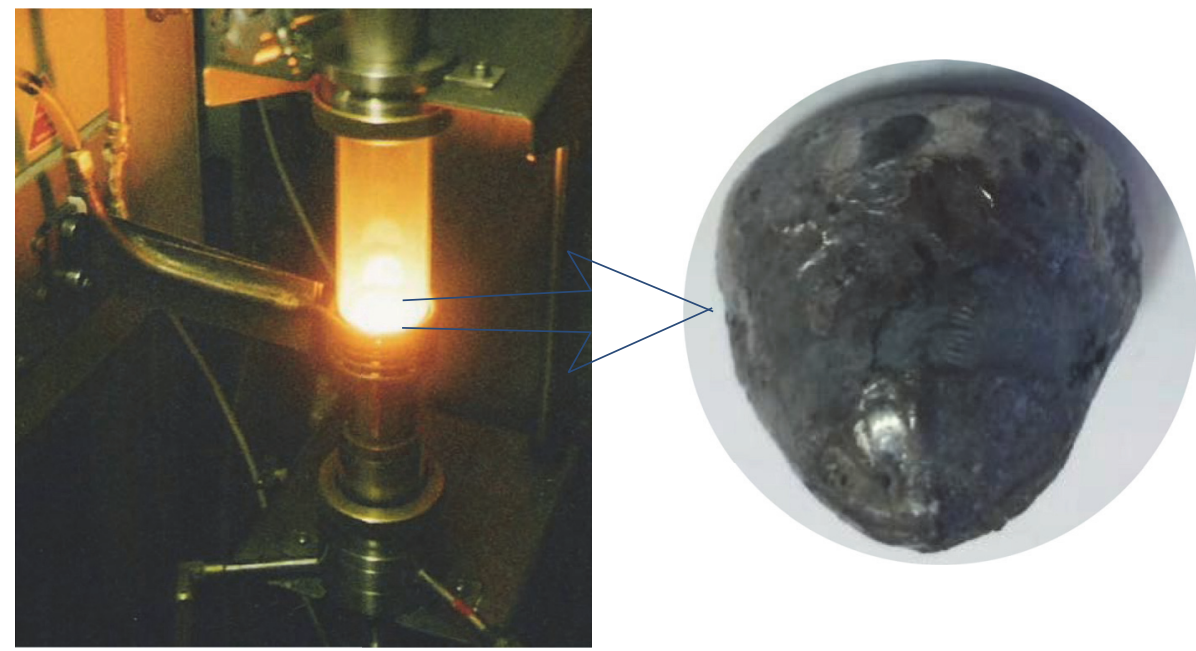

FIGURE 2: The hottest part of the High Frequency Induction furnace during the melting before solidification; view of an obtained ingot.

2.4. Cutting the Ingots for Obtaining the Different Samples. The ingots were cut to obtain different samples. $8 \mathrm{~mm} \times$ $8 \mathrm{~mm} \times 3 \mathrm{~mm}$ parallelepipeds and $15 \mathrm{~mm} \times 2 \mathrm{~mm} \times 1 \mathrm{~mm}$ parallelepipeds were, respectively, prepared for the oxidation runs and for the creep tests. The samples for the oxidation tests were ground with 1200-grit SiC papers with smoothing of their edges and corners. The samples for the creep tests were only ground on their six faces ( $\mathrm{SiC} 1200$-grit papers) and then polished (textile enriched with $1 \mu \mathrm{m}$ hard particles) until obtaining a mirror-like state. High dimensional accuracy was respected for the creep samples (less than $\pm 0.01 \mathrm{~mm}$ of thickness and of width variation from one extremity to the other one).

2.5. Characteristics of the Performed Tests. The samples destined to the high temperature oxidation test were placed in a tubular furnace, in which they were heated up to $1200^{\circ} \mathrm{C}$, maintained at $1200^{\circ} \mathrm{C}$ during 46 hours, and then cooled. The objective was to explore how their microstructures may evolve at high temperature.

The samples destined to the oxidation tests were exposed to a $1.5 \mathrm{~L} / \mathrm{h}$ flow of synthetic air $\left(80 \% \mathrm{~N}_{2}-20 \% \mathrm{O}_{2}\right)$ in a TGA 92.16-18 thermobalance (SETARAM, France). The heating to $1200^{\circ} \mathrm{C}$ at $+20 \mathrm{~K} / \mathrm{min}$ was followed by 46 hours of isothermal oxidation at $1200^{\circ} \mathrm{C}$. Thereafter cooling was done at $-5 \mathrm{~K} / \mathrm{min}$, rate slow enough to allow minimizing the risk of oxide scale spallation. The weight versus time files were plotted to visualize the type and rate of mass gain kinetic. The oxidized samples were coated by cathodic pulverization of gold and then by an electrolytic nickel deposition in order to protect the scales during cutting. The coated samples were then cut in two parts to prepare cross-sections for the metallographic observations.

The samples devoted to the creep tests were placed in a TMA 92.16-18 thermodilatometer (SETARAM, France) equipped with a special apparatus allowing three-point flexural creep. Placed on two bottom supports separated from one another by $12 \mathrm{~mm}$, a central top support applied the constant load. This one was preliminarily calculated, taking into account the exact values of sample thickness and width, to induce a tensile stress of $20 \mathrm{MPa}$ in the middle of the bottom face of the sample. Heating was done up to $1200^{\circ} \mathrm{C}$ at $+20 \mathrm{~K} / \mathrm{min}$, followed by a $1200^{\circ} \mathrm{C}$ dwell maintained until the middle of the bottom part of the sample entered in contact with the apparatus basis (maximal deformation: about $1.4 \mathrm{~mm}$ ). The creep deformation curves were plotted as displacement of the central point versus time.

2.6. Preparation of the Metallographic Samples. For each alloy, the as-cast part, the two halves of the aged part, and the two halves of the oxidized sample were embedded in a cold resin mixture (ESCIL, France). They were ground with $\mathrm{SiC}$ papers from 240-grit up to 1200-grit. They were polished until obtaining mirror-like state with textile enriched with $1 \mu \mathrm{m}$ hard particles. The polished samples were then observed using a Scanning Electron Microscope (SEM) with $20 \mathrm{kV}$ for the acceleration voltage, essentially in the Back Scattered Electrons mode (BSE). Energy Dispersion Spectrometry (EDS) global analyses and spot analyses were carried out to control the alloys' chemical compositions and the phases' compositions.

\section{Results}

3.1. Microstructures of the Alloys in Their As-Cast States and in Their $1200^{\circ} \mathrm{C}$ Aged States. After ad hoc metallographic preparation, the as-cast microstructures and the $1200^{\circ} \mathrm{C}$ aged microstructures of all alloys were observed using the SEM in BSE mode. In the as-cast condition all microstructures are of the same type (Figures 3-7, topside SEM/BSE micrographs):

(i) a dendritic cobalt-based chromium-rich and $\mathrm{M}$ containing matrix,

(ii) an interdendritic network of script-like shaped eutectic MC carbides mixed with the periphery of the proeutectic dendrites, 


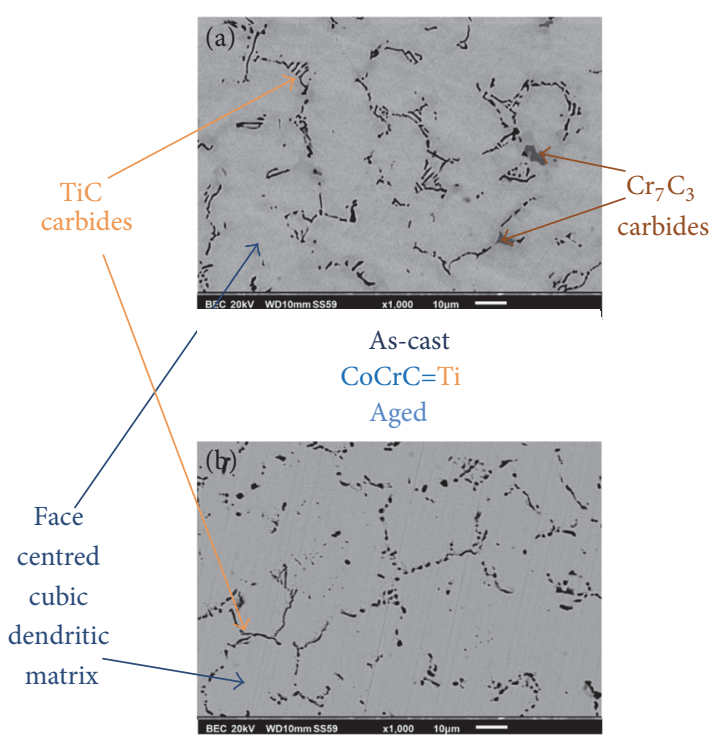

Figure 3: The as-cast (a) and aged (b) microstructure of the "CoCrC=Ti" alloy (SEM/BSE micrographs).

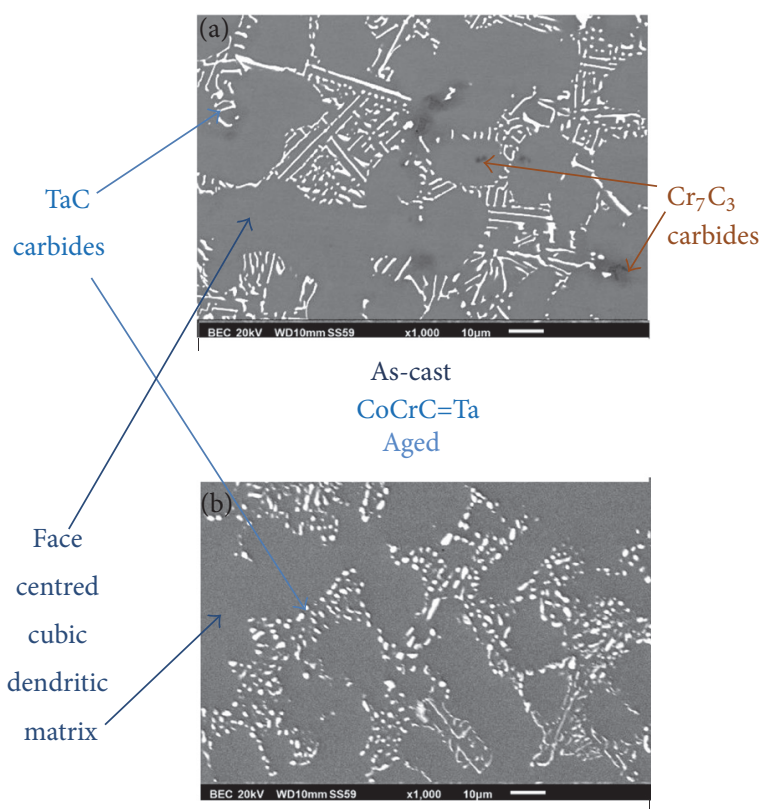

Figure 4: The as-cast (a) and aged (b) microstructure of the "CoCrC=Ta" alloy (SEM/BSE micrographs).

(iii) the additional presence of a few chromium carbides (of the $\mathrm{Cr}_{7} \mathrm{C}_{3}$ type) in the interdendritic boundaries in some cases (the Ti- or Ta-containing alloys).

After about 50 hours isothermally spent at $1200^{\circ} \mathrm{C}$, these initial microstructures have more or less evolved (Figures 37, bottom side SEM/BSE micrographs).

In the "CoCrC=Ti" alloy (Figure 3), the eutectic scriptlike $\mathrm{TiC}$ carbides issued from solidification process are now not really morphologically changed but their surface

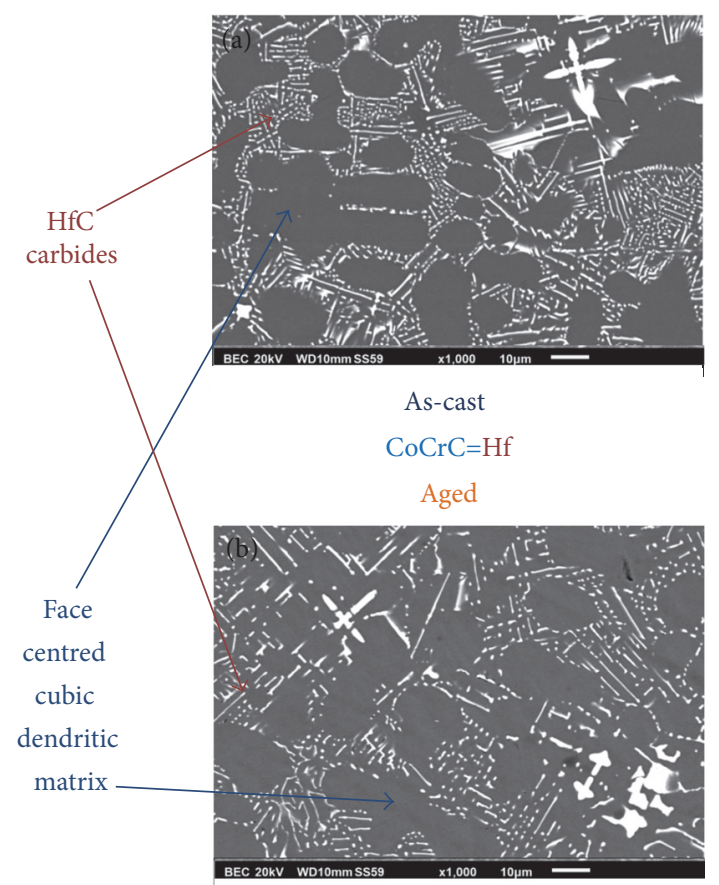

FIgURE 5: The as-cast (a) and aged (b) microstructure of the "CoCrC=Hf" alloy (SEM/BSE micrographs).

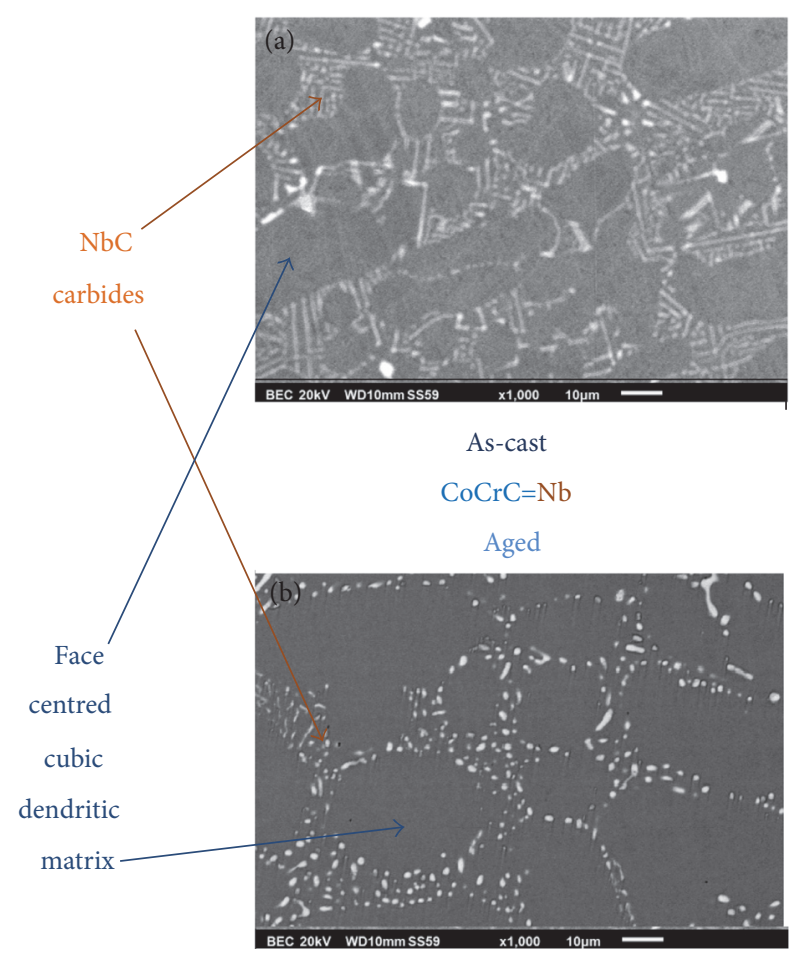

FIgURE 6: The as-cast (a) and aged (b) microstructure of the "CoCrC=Nb" alloy (SEM/BSE micrographs).

fractions seem to be decreased after aging. In addition the chromium carbides have obviously disappeared.

In the " $\mathrm{CoCrC}=\mathrm{Ta}$ " alloy (Figure 4), the eutectic $\mathrm{TaC}$ seem to keep their script-like shape but they are now significantly fragmented. Carbides are not so elongated as in 


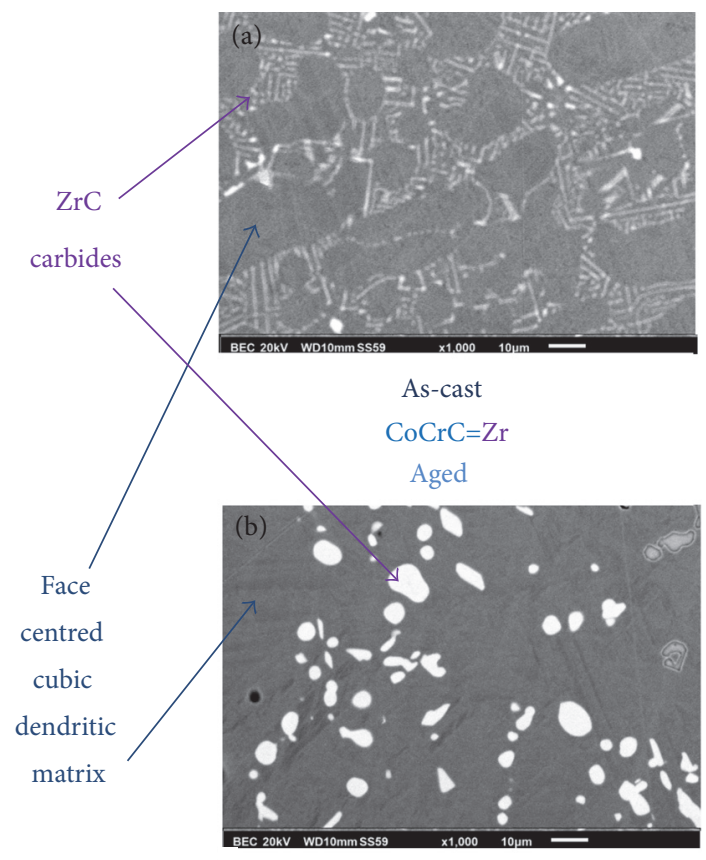

Figure 7: The as-cast (a) and aged (b) microstructure of the "CoCrC=Zr" alloy (SEM/BSE micrographs).

the as-cast state and they are replaced by alignments of small blocky round carbides. Here too, the chromium carbides existing initially have disappeared.

In the " $\mathrm{CoCrC}=\mathrm{Nb}$ " alloy (Figure 5), the same phenomenon as described for the Ta-containing alloy occurred: the initial script-like eutectic $\mathrm{NbC}$ carbides are now significantly fragmented.

In the " $\mathrm{CoCrC}=\mathrm{Hf}$ " alloy (Figure 6), the $\mathrm{HfC}$ are seemingly unchanged after exposure at $1200^{\circ} \mathrm{C}$, either in terms of morphology or in terms of surface fraction.

This is in the "CoCrC=Zr" alloy (Figure 7) that the microstructure has changed the most during the dwell to high temperature: not only did carbides fragment but also significant coalescence was noted. Due to these two phenomena the $\mathrm{ZrC}$ carbides became very coarse and round. They are thus morphologically very different from the initial fine script-like $\mathrm{ZrC}$ carbides.

3.2. Choice of the CoCrC=Hf Alloy. It is clear that the " $\mathrm{CoCrC}=\mathrm{Hf}$ " must be the single alloy to keep for further characterization. Even after fifty hours at the elevated temperature of $1200^{\circ} \mathrm{C}$, its $\mathrm{HfC}$ carbides stayed almost perfectly stable. One can anticipate a long lasting quality of this reinforcing carbides network at high temperature. All the other alloys, maybe except the TiC-reinforced one, encounter more or less severe but always significant carbide fragmentation phenomena. Observing that the script-like $\mathrm{TiC}$ carbide network of the " $\mathrm{CoCrC}=\mathrm{Ti}$ " alloy is less dense than the HfC one of the "CoCrC=Hf" alloy, with consequently probable lower reinforcing effect, this is only the latter one which will be considered for the following tests.
3.3. Flexural Creep of the $\mathrm{CoCrC}=\mathrm{Hf}$ Alloy at $1200^{\circ} \mathrm{C}$. A threepoint flexural creep test was thus performed at $1200^{\circ} \mathrm{C}$ with the parallelepiped sample issued from the " $\mathrm{CoCrC}=\mathrm{Hf}$ " ingot (applied load: the one calculated to induce a $20 \mathrm{MPa}$ tensile stress in the middle of the bottom face). A micrograph shows it before test in Figure 8 (top, right) while another one shows the same sample after 100 hours of test (Figure 8, bottom right): it is only a little deformed, notably by comparison with the "CoCrC=Ta" alloy after only 25 hours in the same conditions (Figure 8, bottom left).

The curves illustrating the deformation kinetic are plotted together in Figure 9. The "CoCrC=Ta" alloy knew first a very short primary creep, then a not really long secondary creep (constant rate of central point displacement), and finally a rapid tertiary creep leading to the contact of the central bottom face of the sample with the alumina support (about $1.4 \mathrm{~mm}$ of total displacement, after 25 hours of test). The "CoCrC=Hf" alloy clearly demonstrated much better resistance against creep deformation in the same conditions since the deformation was only about $200 \mu \mathrm{m}$ after 100 hours of test.

3.4. Oxidation Behaviour of the $\mathrm{CoCrC}=\mathrm{Hf}$ Alloy at $1200^{\circ} \mathrm{C}$. The "CoCrC=Hf" sample was isothermally oxidized at $1200^{\circ} \mathrm{C}$ for 50 hours in synthetic air in the thermobalance. After completed cooling the sample looks like the second macrograph presented in Figure 10(b). By comparison with a sample of " $\mathrm{CoCrC}=\mathrm{Ta}$ " (taken again as reference) having been subjected to the same test, it seems that the surface state of the Hf-containing sample is more irregular, with seemingly a higher average thickness of external oxide.

The mass gain curve of the " $\mathrm{CoCrC}=\mathrm{Hf}$ " alloy is presented in Figure 11 with the one of the " $\mathrm{CoCrC}=\mathrm{Ta}$ " for comparison. The previous comment is confirmed by the mass gain kinetic which is faster for the Hf-containing alloy (after 50 hours, almost twice gain in mass). However, as for the reference Tacontaining alloy, the external oxide scale was continuous and adherent to the substrate, as suggested by the really parabolic shape of both of them.

After cross-section preparation, the surface states and subsurface states were observed using the SEM in BSE mode (Figure 12), and the EDS device for measuring the individual chemical compositions of the oxides. It appears that the "CoCrC=Hf" alloy did not really behave as a chromiaforming alloy since the external scale is mainly composed of spinel oxide $\left(\mathrm{CoCr}_{2} \mathrm{O}_{4}\right)$. Internal oxidation occurred too, with the in situ formation of $\mathrm{HfO}_{2}$ isolated oxides in the subsurface very close to the external oxide/alloy subsurface. The HfC carbides close to the oxidation front were oxidized on place and converted into oxides without release in $\mathrm{Hf}$ in the neighbour parts of matrix which remained totally free in Hf. In contrast, the cross-sectional examination of the subsurface of the "CoCrC=Ta" alloy shows the presence of an external scale of chromia (known to be more protective than the spinel $\mathrm{CoCr}_{2} \mathrm{O}_{4}$ ) and a subsurface internal oxide of the $\mathrm{CrTaO}_{4}$ type, elongated almost continuously along the chromia scale/alloy interface. In addition, a real carbide-free zone developed from the oxidation front inwards the bulk, in this Ta-containing alloy. 


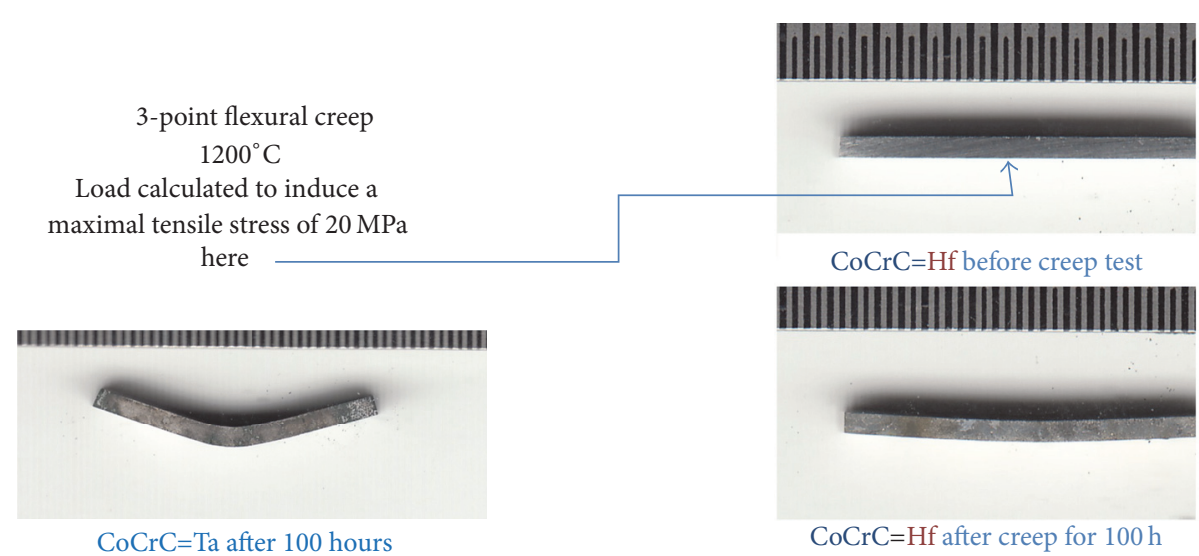

Figure 8: Deformed and oxidized states of the "CoCrC=Ta" alloy (25 hours before contact, left) and of the "CoCrC=Hf" alloy (after 100 hours, right) after creep test at $1200^{\circ} \mathrm{C}$ under a load applied on the top middle to induce a $20 \mathrm{MPa}$ tensile stress.

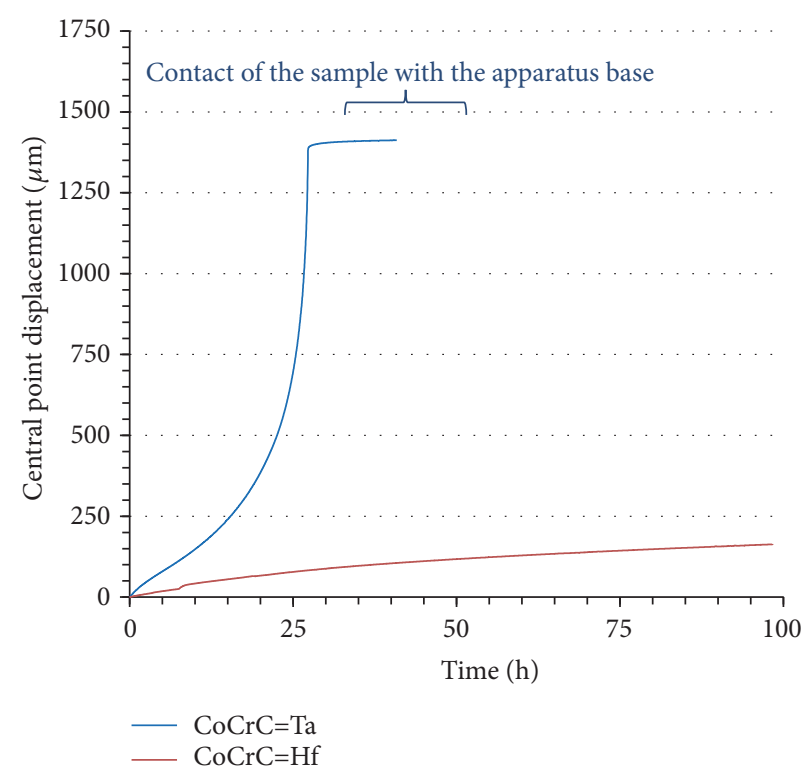

Figure 9: The deformation curves of the "CoCrC=Ta" alloy and of the "CoCrC=Hf" alloy recorded during creep tests at $1200^{\circ} \mathrm{C}$ under a load applied on the top middle to induce a $20 \mathrm{MPa}$ tensile stress.

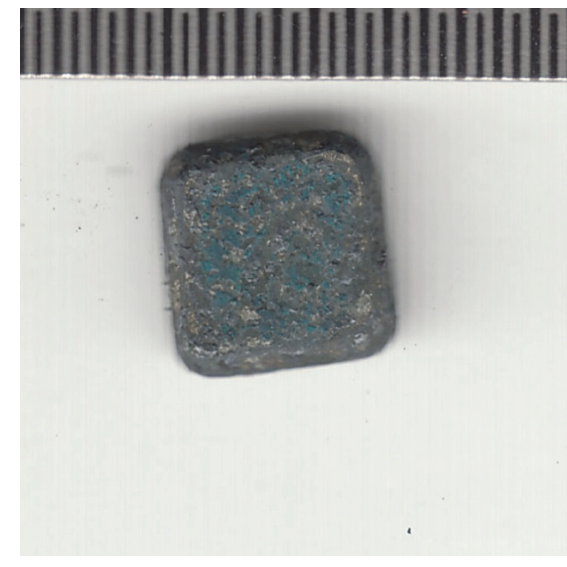

$\mathrm{CoCrC}=\mathrm{Ta}$ oxidized at $1200^{\circ} \mathrm{C}$

(a)

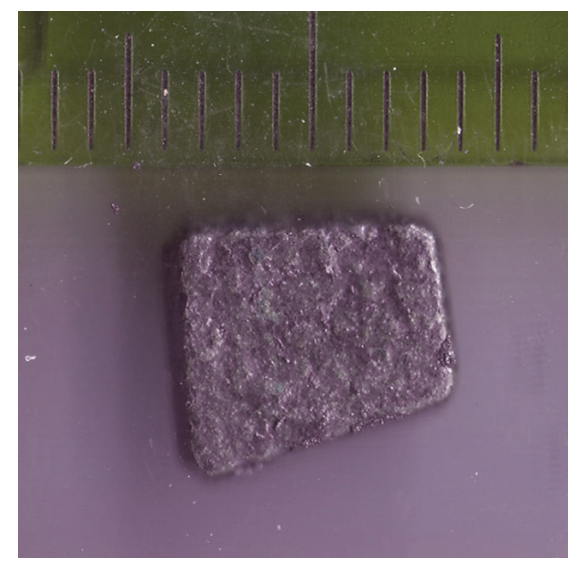

$\mathrm{CoCrC}=\mathrm{Hf}$ oxidized at $1200^{\circ} \mathrm{C}$

(b)

Figure 10: Surface states of the "CoCrC=Ta" alloy oxidized in air at $1200^{\circ} \mathrm{C}$ and cooled at $-5^{\circ} \mathrm{C} \min ^{-1}$ (a) and of the "CoCrC=Hf" alloy oxidized and cooled in the same conditions (b). 


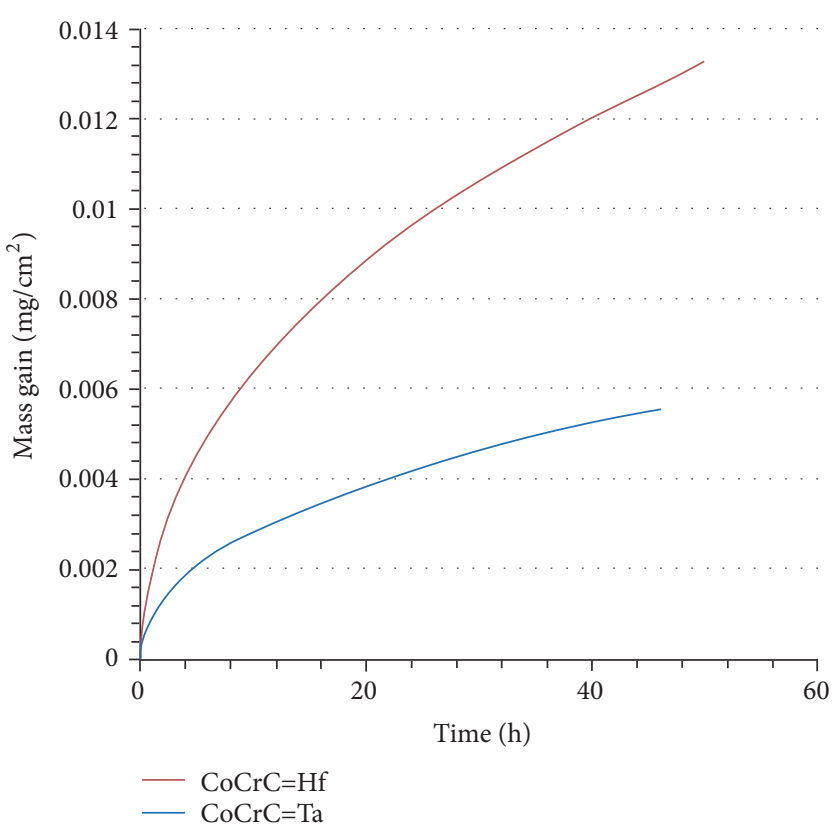

Figure 11: Mass gain curves of the "CoCrC=Ta" alloy and of the "CoCrC=Hf" alloy during their oxidation in air at $1200^{\circ} \mathrm{C}$.

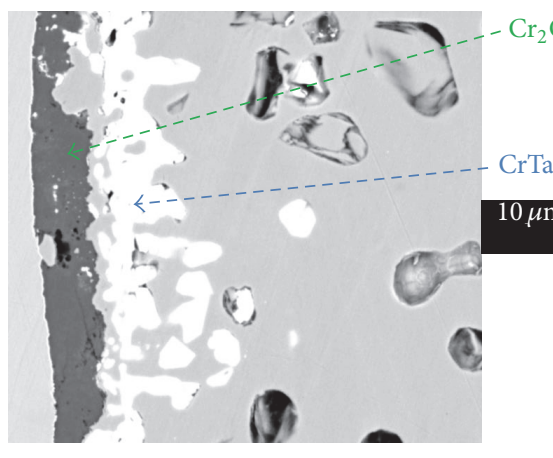

$\mathrm{CoCrC}=\mathrm{Ta}$ oxidized at $1200 \mathrm{C}^{\circ}$

(a)

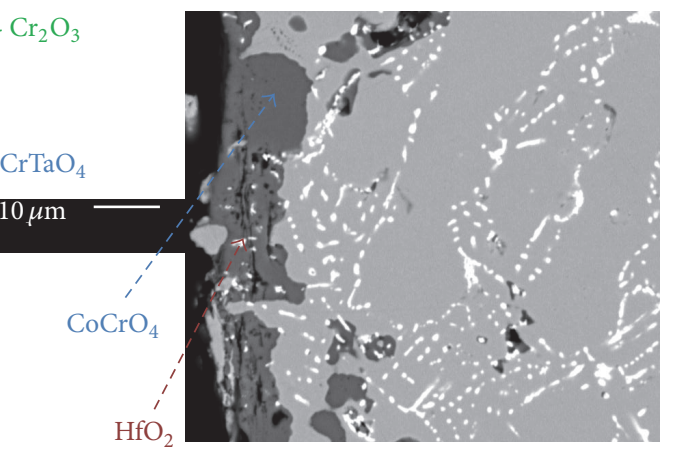

$\mathrm{CoCrC}=\mathrm{Hf}$ oxidized at $1200^{\circ} \mathrm{C}$

(b)

Figure 12: Surface and subsurface states of the "CoCrC=Ta" alloy (a) and of the "CoCrC=Hf" alloy (b) after their oxidation in air at $1200^{\circ} \mathrm{C}$.

\section{Discussion}

Five Co-25Cr-0.5C-xM alloys (wt.\%, with $\mathrm{x}$ defined for having the atomic equivalence with carbon) were thus designed with $\mathrm{M}=\mathrm{Hf}, \mathrm{Ta}, \mathrm{Ti}, \mathrm{Nb}$, or $\mathrm{Zr}$ for promoting the formation of the corresponding MC carbides. This is a rather unusual role for these elements in the chemical compositions of superalloys since their addition is generally done by aiming other objectives. For instance, Hf is a key element in the DS200-Hf directionally solidified superalloy [12]. It is recognized that its addition may influence the microstructure [13] and the properties [14] of superalloys. Niobium, which is considered for superalloys from several decades [15], can be found in substitution into $\mathrm{Al}$ in the gamma prime particles reinforcing the nickel-based single crystalline alloys but it may be chosen as a base element [16]. Tantalum is used in the MarM509 cobalt-based superalloy to form TaC carbides besides chromium carbides $[1,2]$. Titanium, which is a $\gamma^{\prime}$-former element too, as $\mathrm{Al}$ and $\mathrm{Nb}$, may be a base element as in the well-known TA6V alloy [17]. It is involved in different types of aluminides for high temperatures [18]. Zirconium, which can be present in the chemical compositions of superalloys based on cobalt [19] or on nickel [20], is also the main element of the famous Zircaloy-4 [21].

After their elaboration by foundry, the microstructures of the alloys were all of the same type: dendritic matrix and interdendritic script-like MC carbides whatever the $\mathrm{M}$ element. This means that, in a cobalt-chromium base, $\mathrm{TiC}$, $\mathrm{TaC}, \mathrm{NbC}, \mathrm{HfC}$, and $\mathrm{ZrC}$ are carbides more stable than chromium carbides, this confirming what can be expected by considering their free enthalpies of formation. However, the script-like shape inherited from the mechanisms of crystallization at the end of the solidification of the alloys is not 
stable in all cases. Only the HfC carbides demonstrated a high stability at high temperature. Consequently the strengthening effect that can be expected for the alloy may be maintained on long times, what was confirmed by the great creep resistance of the " $\mathrm{CoCrC}=\mathrm{Hf}$ " alloy at $1200^{\circ} \mathrm{C}$ under flexural constant solicitation inducing a significant tensile stress. The observed performance is particularly remarkable since this alloy is a simple equiaxed polycrystalline alloy, as is to say of a type which is usually not considered for applications under stress at so high temperature.

The reason of this particularly good mechanical behaviour at $1200^{\circ} \mathrm{C}$ is obviously due to the volume fraction and morphologic sustainability of these HfC carbides, as proven by the much worse creep behaviour of the "CoCrC=Ta" alloys, the script-like interdendritic $\mathrm{TaC}$ carbides of which quickly fragmented. Obviously, the interdendritic cohesion brought by the mix of the periphery of dendrites with the script-like $\mathrm{HfC}$ carbides was really efficient for delaying much later the beginning of the third stage of creep (the one concerned by the coalescence of the cavities resulting of the accumulation of the dislocation in the interdendritic boundaries). However the rather short secondary stage of the "CoCrC=Ta" alloy's creep was itself faster than the one of the "CoCrC=Hf" alloy, despite the presence of Ta atoms in solid solution in the matrix, while no $\mathrm{Hf}$ atoms were detected in the matrix of the "CoCrC=Hf" alloy. This is questionable and need further investigations to understand such difference of secondary creep deformation rate between the two alloys. But the main reason of the mechanical supremacy demonstrated by the $\mathrm{CoCrC}=\mathrm{Hf}$ alloy during the creep bending test may be the probable high resistance of the HfC carbide network to the local disorientation of the alloy under the mechanical torque which is maximal in the central part of the sample. Indeed, this torque, accompanied by particularly intense shear, favours a local rotation which cannot be obstructed by $\mathrm{TaC}$ rounded carbides which move instead of resisting, but to which morphologically not affected HfC elongated script-like carbides may more efficiently resist. This is probably here the key of the folding resistance of the HfC-strengthened sample.

Concerning the high temperature oxidation behaviours, the one of the " $\mathrm{CoCrC}=\mathrm{Hf}$ " alloy was not catastrophic but significantly worse than the "CoCrC=Ta" alloy's one. Indeed the Hf-containing alloy oxidized according to Wagner's law (parabolic shape), this demonstrating a protection effect of the continuous external oxide layer, but faster than the Tacontaining one. An explanation for that is the nature of the oxide scales formed on surface, which is more a spinel oxide than really chromia as for the Ta-containing alloy. Obviously, the presence of high quantity of $\mathrm{Hf}$, more precisely of great fraction of interdendritic HfC carbides, was deleterious in this field, possibly by obstructing chromium diffusion along the interdendritic boundaries since $\mathrm{HfC}$ carbides remained as carbides or as oxides in these locations, even close to the oxidation front. For the Ta-containing alloy, for which a TaCfree zone developed from the oxidation front, the chromium diffusion was not obstructed along the interdendritic boundaries over several tens (first hours) or hundreds (100 hours and later) of micrometres in depth.

\section{Conclusion}

The HfC strengthening of equiaxed polycrystalline cobaltchromium alloys studied in this work appeared very promising for their creep resistance. As demonstrated here by letting competing different MC carbides in the same base, this systems emerged above the others, with additionally the explanation of this superiority: high stability of HfC allowing them resisting both volume fraction decrease and fragmentation. This Co-25Cr-0.5C-7.4Hf alloy may represent a metallic solution for applications at $1200^{\circ} \mathrm{C}$ (and maybe more), thus an alternative way besides ceramics which allows high toughness and crack propagation resistance thanks to the metallic nature of this material. The creep resistance may be improved again by hardening matrix and its high temperature oxidation resistance, currently at a level not high enough, must be itself significantly improved to expect profiting of this major creep resistance at elevated temperature.

\section{Conflicts of Interest}

The author declares that they have no conflicts of interest.

\section{Acknowledgments}

The author is grateful to Mélissa Ritouet-Léglise, Elodie Conrath, Mira Khair, Jérémy Peultier, and Valentin Kuhn for their contributions to this work, as well as to Thierry Schweitzer who carefully prepared the samples for the oxidation and creep tests.

\section{References}

[1] C. Sims and W. Hagel, The Superalloys, John Wiley \& Sons, New York, NY, USA, 1972.

[2] E. Bradley, Superalloys: A Technical Guide, ASM International, Metals Park, Ohio, USA, 1988.

[3] M. J. Donachie and S. J. Donachie, Superalloys: A Technical Guide, ASM International, Materials Park, Ohio, USA, 2nd edition, 2002.

[4] E. Nembach and G. Neite, "Precipitation hardening of superalloys by ordered $\gamma^{\prime}$-particles," Progress in Materials Science, vol. 29, no. 3, pp. 177-319, 1985.

[5] C. Cui, D. Ping, Y. Gu, and H. Harada, "A new co-base superalloy strengthened by $\gamma^{\prime}$ phase," Materials Transactions, vol. 47, no. 8, pp. 2099-2102, 2006.

[6] B. Mishra, M. Ionescu, and T. Chandra, "Feasability of cast and wrought Co-Al-W-X gamma prime superalloys," Materials Science Forum, vol. 783-786, pp. 1159-1164, 2013.

[7] M. Klauke, D. Mukherji, B. Gorr, V. B. Da Trindade Filho, J. Rösler, and H.-J. Christ, "Oxidation behaviour of experimental Co-Re-base alloys in laboratory air at $1000 \circ \mathrm{C}$," International Journal of Materials Research, vol. 100, no. 1, pp. 104-111, 2009.

[8] B. Gorr, S. Burk, T. Depka et al., "Effect of Si addition on the oxidation resistance of $\mathrm{Co}-\mathrm{Re}-\mathrm{Cr}$-alloys: recent attainments in the development of novel alloys," International Journal of Materials Research, vol. 103, no. 1, pp. 24-30, 2012.

[9] B. Gorr, M. Azim, H.-J. Christ et al., "Microstructure Evolution in a New Refractory High-Entropy Alloy W-Mo-Cr-Ti-Al," 
Metallurgical and Materials Transactions A: Physical Metallurgy and Materials Science, vol. 47, no. 2, pp. 961-970, 2016.

[10] P. Berthod, "High temperature properties of several chromiumcontaining Co-based alloys reinforced by different types of MC carbides (M = Ta, Nb, Hf and/or Zr)," Journal of Alloys and Compounds, vol. 481, no. 1-2, pp. 746-754, 2009.

[11] S. R. Shatynski, "The thermochemistry of transition metal carbides," Oxidation of Metals, vol. 13, no. 2, pp. 105-118, 1979.

[12] A. Baldan, "Microstructural investigation of DS200 + Hf superalloy," Zeitschrift fuer Metallkunde/Materials Research and Advanced Techniques, vol. 80, no. 9, pp. 635-642, 1989.

[13] P. S. Kotval, J. D. Venables, and R. W. Calder, "Role of hafnium in modifying the microstructure of cast nickel-base superalloys," Met Trans, vol. 3, no. 2, pp. 453-458, 1972.

[14] Y. Murata, K. Suga, and N. Yukawa, "Effect of transition elements on the properties of MC carbides in IN-100 nickel-based superalloy," Journal of Materials Science, vol. 21, no. 10, pp. 36533660, 1986.

[15] C. T. Sims, "Niobium in superalloys: a perspective," High Temperature Technology, vol. 2, no. 4, pp. 185-201, 1984.

[16] M. C. Dropmann, D. Stover, H. P. Buchkremer, and R. M. German, "Properties and processing of niobium superalloys by injection molding," in Advances in Powder Metallurgy and Particulate Materials, vol. 8, pp. 213-224, Metal Powder Industries Federation, 1992.

[17] Y. Zhai, D. A. Lados, E. J. Brown, and G. N. Vigilante, "Fatigue crack growth behavior and microstructural mechanisms in Ti$6 \mathrm{Al}-4 \mathrm{~V}$ manufactured by laser engineered net shaping," International Journal of Fatigue, vol. 93, no. 1, pp. 51-63, 2016.

[18] B. Chen, H. Xiong, B. Sun, S. Tang, B. Du, and N. Li, "Microstructures and mechanical properties of Ti3Al/Ni-based superalloy joints arc welded with Ti-Nb and Ti-Ni-Nb filler alloys," Progress in Natural Science: Materials International, vol. 24, no. 4, pp. 313-320, 2014.

[19] Z. Opiekun, "Influence of zirconium and heat treatment on the structure of heat-resistant cobalt casting alloys of MAR-M509 type," Journal of Materials Science, vol. 22, no. 5, pp. 1547-1556, 1987.

[20] Y.-L. Tsai, S.-F. Wang, H.-Y. Bor, and Y.-F. Hsu, "Effects of Zr addition on the microstructure and mechanical behavior of a fine-grained nickel-based superalloy at elevated temperatures," Materials Science and Engineering A, vol. 607, pp. 294-301, 2014.

[21] H. Paul, M. Darrieulat, N. Vanderesse, L. Lityńska, and M. Miszczyk, "Microstructure of warm worked Zircalloy-4," Archives of Metallurgy and Materials, vol. 55, no. 4, pp. 1007-1019, 2010. 

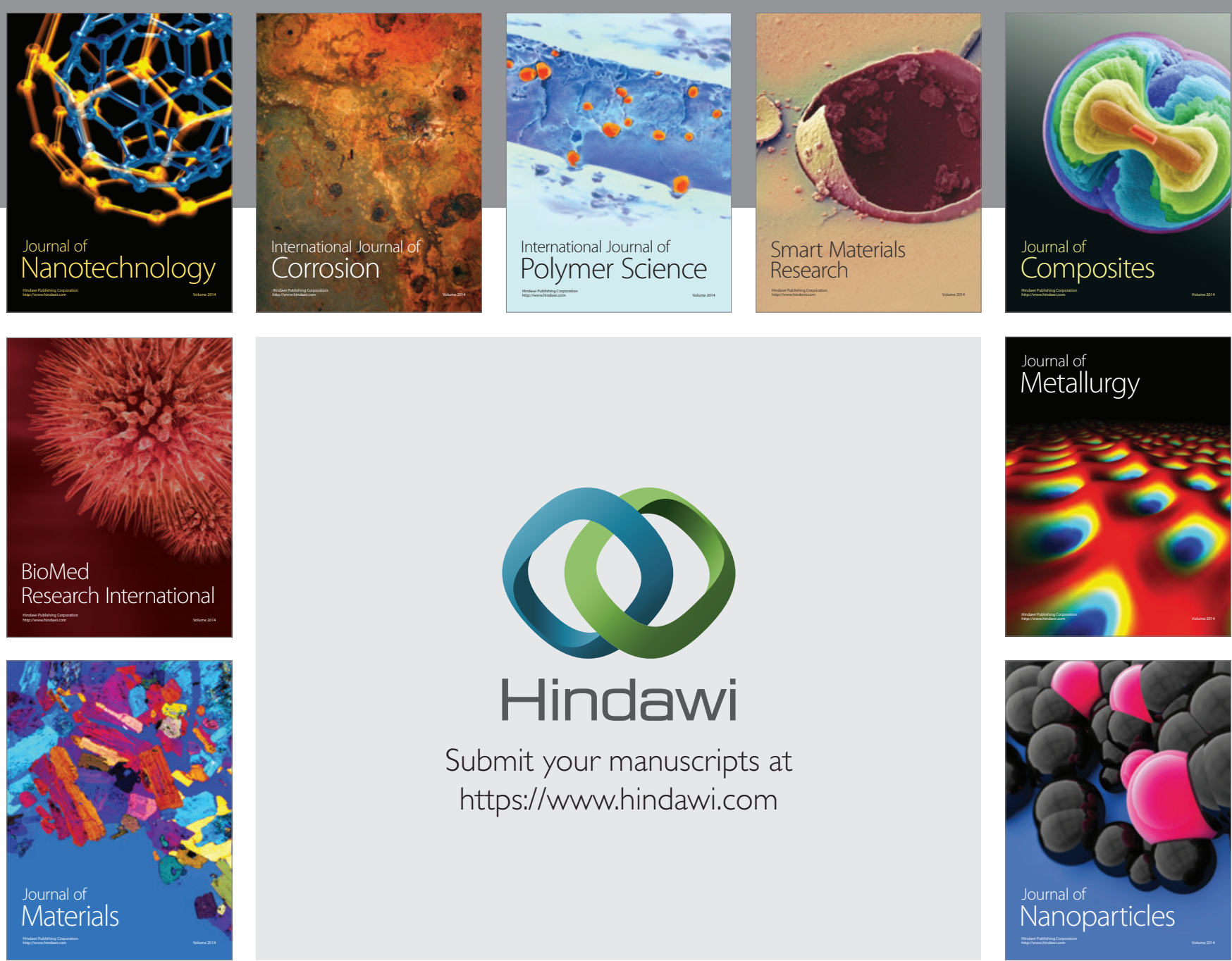

\section{Hindawi}

Submit your manuscripts at

https://www.hindawi.com

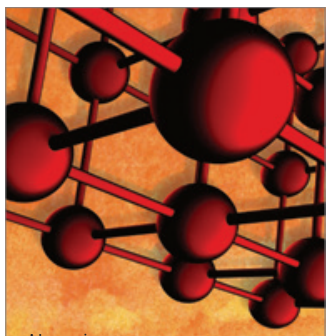

Materials Science and Engineering
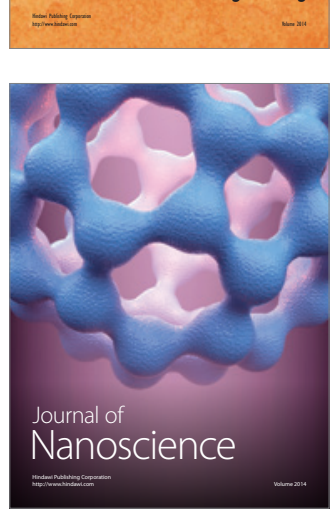
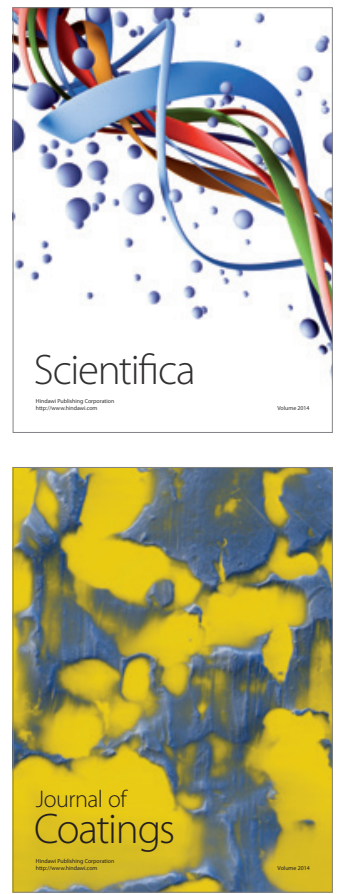
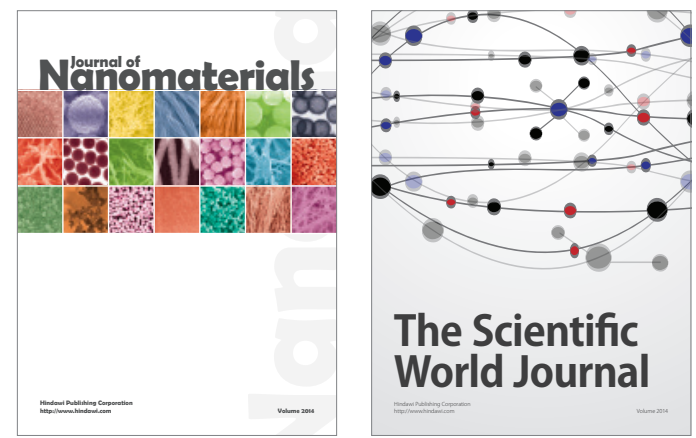

The Scientific World Journal
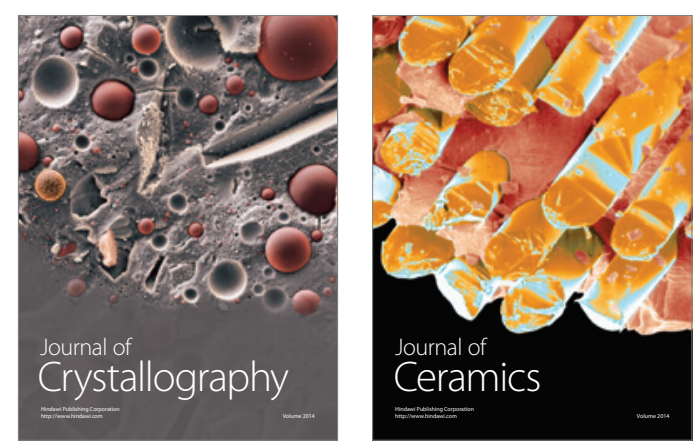
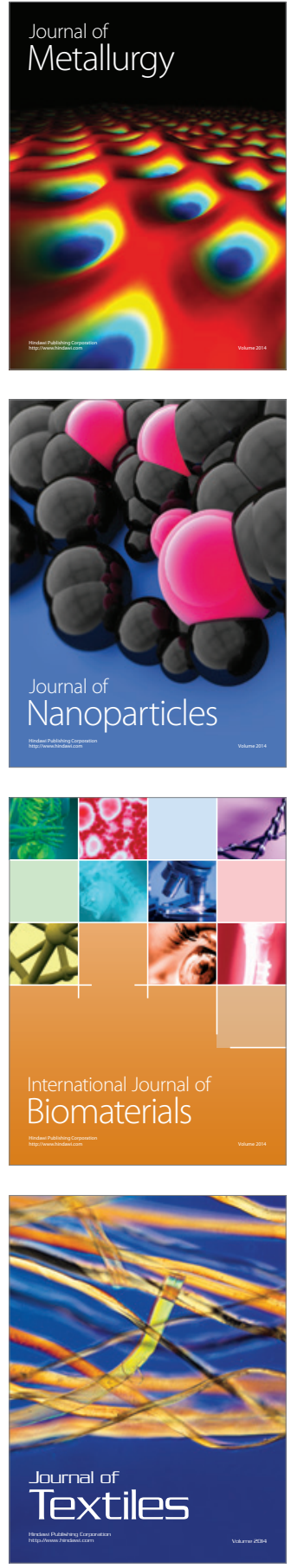